\title{
Qualidade pós-colheita de bulbos de cebola 'população botucatu' produzidos no semiárido brasileiro e armazenados sob temperatura ambiente
}

\author{
Postharvest quality of onion bullbs 'botucatu polpulation' produced in the brazilian semi-arid and
} stored under room temperature

Calidad postharvest de bulbos de cebolla 'población Botucatu' producido en el semiárido brasileño y Almacenado bajo temperatura ambiente

Fabrício Teixeira de Almeida

ORCID: https://orcid.org/0000-0002-5280-4188 Universidade Federal do Vale do São Francisco, Brasil E-mail: fteixeira.univasf@hotmail.com

Acácio Figueiredo Neto

ORCID: https://orcid.org/0000-0002-0326-9123 Universidade Federal do Vale do São Francisco, Brasil E-mail: figueiredoacacio@gmail.com

Carlos Antonio Fernandes Santos ORCID: https://orcid.org/ 0000-0002-6932-6805 Embrapa Semiárido, Brasil

E-mail: caslos-fernandes.santos@embrapa.br Marylia Sousa Costa

ORCID: https://orcid.org/0000-0001-9593-4233 Universidade Federal de Campina Grande, Brasil E-mail: marylia.sousacosta@gmail.com

Bruno Emanuel Souza Coelho

ORCID: https://orcid.org/0000-0002-4526-6369 Universidade Federal do Vale do São Francisco, Brasil E-mail: souza.coelho18@gmail.com

Izaías da Silva Lima Neto

ORCID: https://orcid.org/0000-0002-7557-1102 Universidade Federal do Vale do São Francisco, Brasil

E-mail: izaias.limaneto@univasf.edu.br

Carlos Alberto Aragão

ORCID: https://orcid.org/0000-0003-3430-8196 Universidade do Estado da Bahia, Brasil

E-mail: carlosaragao@ hotmail.com

Alciene Pacheco da Silva

ORCID: https://orcid.org/0000-0003-4117-2792 Universidade Federal do Vale do São Francisco, Brasil

E-mail:alcienepsclaro@gmail.com

\begin{abstract}
Resumo
A cebola é uma cultura economicamente importante para o Brasil e sua produção vem crescendo em diversas regiões do país. A região do Vale do São Francisco é considerada de grande potencial agrícola, atraindo diversos investimentos em agricultura. A maior conservação pós-colheita é importante para ocasião da comercialização da cebola, que apresenta grandes variações de preços, em curtos períodos de tempo. O produtor em função do conhecimento das perdas de massa poderá alcançar melhores cotações de preços e incrementar seus lucros, em função da volatilidade do mercado ceboleiro. Este trabalho teve como objetivo avaliar características físico-químicas e perdas pós-colheita da cultivar "População Botucatu" produzida na Estação Experimental Bebedouro, pertencente a EMBRAPA Semiárido, Petrolina (PE). O delineamento estatístico utilizado foi inteiramente casualizado com 6 tratamentos e 6 repetições. Os experimentos foram realizados no Laboratório de Armazenamento de Produtos Agrícolas (LAPA) do Colegiado de Engenharia Agrícola e Ambiental da UNIVASF em Juazeiro (BA). Os bulbos foram armazenados sob condições ambiente de $27^{\circ} \mathrm{C} \pm 2^{\circ} \mathrm{C}$ e umidade relativa de $75 \% \pm 5 \%$ durante 75 dias. Onde observou que os bulbos armazenados em temperatura ambiente têm perdas de massa significativas em relação ao tempo de armazenamento principalmente a partir de 45 dias.
\end{abstract}

Palavras-chave: Caracterização físico-química; Hortaliça; Produtos agrícolas. 


\begin{abstract}
Onions are an economically important crop for Brazil and its production has been growing in several regions of the country. The São Francisco Valley region is considered of great agricultural potential, attracting several investments in agriculture. The greater post-harvest conservation is important for the occasion of the commercialization of onions, which presents large price variations in short periods of time. The producer, depending on the knowledge of mass losses, will be able to achieve better price quotes and increase their profits, due to the volatility of the ceboleiro Market. This study aimed to evaluate physical-chemical characteristics and postharvest losses of the cultivar "Botucatu Population" produced at the Bebedouro Experimental Station, belonging to EMBRAPA Semiarid, Petrolina (PE). The statistical design used was completely randomized with 6 treatments and 6 replicates. The experiments were carried out at the Agricultural Products Storage Laboratory (LAPA) of the Agricultural and Environmental Engineering Collegiate of UNIVASF in Juazeiro (BA). The bulbs were stored under ambient conditions of $27^{\circ} \mathrm{C} \pm 2{ }^{\circ} \mathrm{C}$ and relative humidity of $75 \% \pm 5 \%$ for 75 days. Where he observed that bulbs stored at room temperature have significant mass losses in relation to storage time mainly from 45 days.
\end{abstract}

Keywords: Physicochemical characterization; Vegetable; Agricultural products.

\title{
Resumen
}

Las cebollas son un cultivo económicamente importante para Brasil y su producción ha estado creciendo en varias regiones del país. La región del Valle de San Francisco se considera potencial agrícola, atrayendo diversas inversiones en agricultura. Una mayor conservación posterior a la cosecha es importante para la comercialización de cebollas, que muestra grandes variaciones de precios en períodos cortos de Hora. El productor, dependiendo del conocimiento de las pérdidas masivas, puede precios y aumentar sus beneficios, debido a la volatilidad de la mercado ceboleiro. Este estudio tenía como objetivo evaluar las características físico-químicas y las pérdidas postharvest del cultivar "Población Botucatu" producido en la Estación Experimental de Bebedouro, perteneciente a EMBRAPA Semiarid, Petrolina (PE). El diseño estadístico fue completamente aleatorizado con 6 tratamientos y 6 réplicas. Los experimentos se llevaron a cabo en el Laboratorio de Almacenamiento de Productos Agrícolas (LAPA) de la Colegiata de Ingeniería Agrícola y Ambiental UNIVASF en Juazeiro (BA). Las bombillas se almacenaban en condiciones ambientales $27^{\circ} \mathrm{C} \pm 2^{\circ} \mathrm{C}$ y humedad relativa del $75 \% \pm 5 \%$ durante 75 días. Donde señaló que bombillas almacenadas a temperatura ambiente tienen pérdidas de masa significativas en comparación con el tiempo de almacenamiento principalmente a partir de 45 días.

Palabras-clave: Caracterización físicoquímica; Vegetación; Productos agrícolas.

\section{Introdução}

A cebola (Allium cepa L.) tem grande importância socioeconômica a nível mundial, pois é a terceira olerícola mais cultivada, ficando atrás apenas da batata (Solanum tuberosum L.) e do tomate (Solanurn lycopersicum L.) (FAO, 2013). No Brasil, em 2018, foram destinados 57. 474 hectares para o plantio de cebola, com rendimento médio de 28 t ha-1. A produção de cebola no Brasil concentra-se principalmente na região Sul, responsável por $50 \%$ da produção nacional, seguida pela região Sudeste $(23,9 \%)$, Nordeste $(18,5 \%)$ e Centro-Oeste (7,6\%) (IBGE, 2017).

No Nordeste brasileiro, esta hortaliça é amplamente produzida no Vale do São Francisco, sendo os estados de Pernambuco e Bahia os maiores produtores, respondem por 97,9\% da produção regional, com produtividade média de 24,9 e 29,8 t ha -1, respectivamente (IBGE, 2017). O Nordeste tem o diferencial de ser a única região brasileira com condições de ofertar o produto durante todos os meses do ano devido às condições climáticas favoráveis ao desenvolvimento da cultura (Araújo \& Correia, 2007).

Em Pernambuco, o período de maior disponibilidade deste produto no Centro de Abastecimento e Logística (CEASAPE) vai de agosto a dezembro. Os principais municípios nordestinos que abastecem o CEASA são Petrolina, Cabrobó e Belém de São Francisco, os quais são localizados no estado de Pernambuco, e Casa Nova, Juazeiro, Irecê e Mucugê, que por sua vez situam-se no estado Bahia (CEASA, 2018).

A cebola como a maioria dos produtos agrícolas sazonais, tem grande variação de preços. Normalmente, os menores preços de mercado coincidem com o período da safra e os maiores com a entre safra. Isso faz com que a armazenagem seja uma alternativa em busca das melhores remunerações. Os bulbos das cebolas resistem razoavelmente a armazenagem até aproximadamente 180 dias, mas dependendo das condições de armazenagem e qualidade dos bulbos, estão sujeitos a perdas que por vezes podem inviabilizar a prática (Marconatto, 2017). 
Entre os problemas enfrentados pelos produtores estão as perdas no período da armazenagem da cebola, estimadas em aproximadamente $30 \%$ durante a fase de pós-colheita, que por muitas vezes inviabiliza a própria armazenagem. O Instituto Centro de Economia e Planejamento Agrícola (ICEPA) estimou para a safra 2013 perdas em torno de 27\% da cebola colhida (ICEPA, 2013).

Os danos e perdas na pós-colheita normalmente são consequência das condições de armazenamento, entre elas a temperatura, umidade, luminosidade, ventilação e composição gasosa, que podem comprometer a conservação dos bulbos induzindo a processos metabólicos que modificam a sua composição química, facilitando a ocorrência de danos microbiológicos (podridão), perda de peso (desidratação), flacidez (falta de turgescência), brotação e enraizamento (Marconatto, 2017).

Segundo Figueiredo Neto (2014), para se obter período mais longo de armazenamento da cebola, alguns pontos devem ser considerados, como a escolha do cultivar, quantidade e tipos de fertilizantes utilizados, tempo de colheita, cura e as características dos locais de armazenamento.

Esse trabalho teve como objetivo avaliar a qualidade pós-colheita de cebola 'população botucatu' armazenada em temperatura ambiente.

\section{Metodologia}

O cultivo e a colheita da cebola 'população botucatu', foi realizada na Estação Experimental Bebedouro, pertencente a Embrapa Semiárido, em Petrolina (PE). O clima da região é do tipo BSwh, segundo a classificação de Köppen, com precipitação média anual de 360 milímetros, temperatura média anual de $26,8^{\circ} \mathrm{C}$, umidade relativa do ar de $65 \%$, e vegetação nativa de Caatinga hiperxerófila.

O manejo cultural da cebola baseou-se nas recomendações de plantio para a região, sendo a colheita aos 85 dias após o transplantio e 125 dias após o preparo da sementeira.

Os bulbos foram colhidos manualmente, considerando os que estivessem com maturação completa ou "estalados", fazendo do se uma análise qualitativa quando se fala em aspecto comercial e coloração atrativa, descartando-se aqueles que apresentaram lesões causadas por pragas ou doenças, ou fora dos padrões de tamanho. A cura ocorreu de forma natural (ao sol) na qual depois de arrancados os bulbos do solo, esses foram enfileirados de forma que suas palhadas proporcionassem a proteção dos bulbos adjacentes da incidência direta do sol.

Após um período de 7 (sete) dias, os bulbos foram separados dos talos, retirados o excesso de terra e selecionados os que apresentavam maior diâmetro.

Em seguida foram levados ao LAPA, onde foram devidamente identificados. Os bulbos foram armazenados sob condições ambiente de $27^{\circ} \mathrm{C} \pm 2^{\circ} \mathrm{C}$ e umidade relativa de $75 \% \pm 5 \%$ durante 75 dias. Avaliou-se o tempo de vida de prateleira durante 75 dias em cada ciclo distinto de análise, com a verificação quantitativa através dos parâmetros físico-químicos quanto a: perda de massa - A perda de massa foi determinada utilizando-se uma balança semi-analítica tendo seus resultados expressos em porcentagem; cor (L, $a^{*}$ e b*) Sistema CIELab - Os parâmetros de cor foram determinados utilizando espectrofotômetro colorímetro Minolta CR 400®, com sistema de cor CIELab, obtendo-se os valores de $\mathrm{L}^{*}$, $\mathrm{a}^{*}$ e $\mathrm{b}^{*}$; onde o $\mathrm{L}^{*}$ determina a luminosidade, a* a transição da cor verde (-a*) para a cor vermelha $\left(+a^{*}\right)$ e b* a transição da cor azul (-b*) para a cor amarela $\left(+b^{*}\right)$ com vistas a avaliar as alterações na cor dos bulbos enquanto estavam armazenados; Índice de Diferença de Absorbância (Índice DA) - O índice DA foi obtido através de espectrofotômetro portátil (DA-meter®, Turoni, Itália) estimado pela diferença entre os valores de absorbância medidos em 670nm e 720nm (Noferini et al., 2009), e próximos do pico de absorção da clorofila. Sendo este índice mensurado em ambos os lados de cada amostra, considerando-se para avaliação estatística a média; Tamanho (mm): Os parâmetros de tamanho (comprimento e diâmetro) foram determinados utilizando-se um 
paquímetro digital de precisão $0,05 \mathrm{~mm} ; \mathrm{pH}$ - Foi determinado diretamente no suco, utilizando-se um potenciômetro digital de acordo com as normas da Association of Official Analytical Chemists ( AOAC, 2002); Sólidos Solúveis (SS) - Os sólidos solúveis (SS) foram determinados utilizando líquido necessário e nítido para leitura direta em refratômetro digital portátil Hanna HI e os resultados expressos em ${ }^{\circ}$ Brix; Relação SS/AT (Ratio) - Foi obtido pela divisão dos sólidos solúveis totais pela acidez titulável; Acidez Titulável - Foi realizada utilizando método acidimétrico, onde as amostras foram tituladas com $5 \mathrm{~g}$ do extrato vegetal, adicionado $50 \mathrm{~mL}$ de água destilada e 3 gotas de fenolftaleína a $1 \%$. A solução contendo a amostra será titulada com $\mathrm{NaOH}$ 0,1 mol.L-1, até atingir o ponto de viragem do indicador fenolftaleína. A acidez titulável foi expressa como porcentagem de ácido pirúvico presente na cebola. Com base nas análises anteriormente mencionadas, a cada 15 dias foram feitas nas cebolas, iniciando no dia zero $(0,15,30,45,60$ e 75 dias) totalizando 6 (seis) tempos com armazenamento sob temperatura ambiente.

Foi utilizado o delineamento experimental inteiramente casualizado (DIC), com seis repetições e seis tratamentos, que corresponderam aos seis tempos de armazenamento $(0,15,30,45,60$ e 75 dias) para as análises de acidez titulável, obrix, cor, pH. Os dados foram submetidos a análise de variância e testes de regressão utilizando o programa do software Assistat, Versão 7.7 beta (Silva \& Azevedo, 2016).

\section{Resultados e Discussão}

Observando os dados presentes na Tabela 1, pode-se perceber que para os parâmetros de relação de diâmetros, Índice de diferença de absorbância- DA e a luminosidade $\left(L^{*}\right)$, tiveram resultados não significativos $(P>0,05)$, não havendo diferença significativa para esses parâmetros.

Tabela 1. Síntese da análise de variância dos valores médios das características físicas da cebola "População Botucatu" em temperatura ambiente.

\begin{tabular}{lccccc}
\hline \multirow{2}{*}{$\begin{array}{c}\text { Tempo de armazenamento } \\
\text { (dias) }\end{array}$} & $\begin{array}{c}\text { Relação de } \\
\text { diametros }\end{array}$ & DA & \multicolumn{3}{c}{ Cor } \\
\cline { 5 - 6 } & $0,89 \mathrm{a}$ & $0,11 \mathrm{a}$ & $60,39 \mathrm{a}$ & $9,64 \mathrm{~b}$ & $25,1 \mathrm{~b}$ \\
\hline 0 & $0,91 \mathrm{a}$ & $0,10 \mathrm{a}$ & $57,73 \mathrm{a}$ & $14,7 \mathrm{ab}$ & $27,3 \mathrm{ab}$ \\
15 & $0,97 \mathrm{a}$ & $0,09 \mathrm{a}$ & $61,05 \mathrm{a}$ & $15,0 \mathrm{ab}$ & $30,5 \mathrm{a}$ \\
30 & $0,89 \mathrm{a}$ & $0,32 \mathrm{a}$ & $62,89 \mathrm{a}$ & $12,6 \mathrm{ab}$ & $27,1 \mathrm{ab}$ \\
45 & $0,97 \mathrm{a}$ & $0,23 \mathrm{a}$ & $63,06 \mathrm{a}$ & $12,6 \mathrm{ab}$ & $28,5 \mathrm{ab}$ \\
60 & $0,95 \mathrm{a}$ & $0,11 \mathrm{a}$ & $59,89 \mathrm{a}$ & $12,6 \mathrm{a}$ & $29,1 \mathrm{ab}$ \\
75 & $0,8 \mathrm{~ns}$ & $2,4 \mathrm{~ns}$ & $1,0 \mathrm{~ns}$ & $2,8 *$ & $2,2 \mathrm{~ns}$ \\
Fator F & 11.47 & 90,87 & 10,89 & 36,41 & 15,24 \\
\hline CV\% & &
\end{tabular}

Médias seguidas de mesma letra na coluna não diferem pelo Teste de Tukey. ns: não significativo $(\mathrm{P}>0,05)$; *: significativo $(\mathrm{P}<0,05)$; **: significativo $(\mathrm{P} \leq 0,01)$. CV: coeficiente de variação $(\%)$. Fonte: Autores.

As cebolas da variedade 'população botucatu' quando analisadas durante todo o tempo de armazenamento, não apresentaram redução de sua luminosidade, apresentado ainda brilho resultados estes convergentes com os encontrados por Melo et al. (2010) em sua pesquisa com cebolas da variedade Beta cristal e Óptima. As dimensões das cebolas não apresentaram redução de tamanho com o passar dos dias de armazenamento, assim como também o índice DA, o qual não representou um parâmetro com respostas significativas para avaliação da qualidade das cebolas durante o armazenamento tendo em vista que não houve diferença entre as médias obtidas. Já em relação a cor ( $a^{*}$ e b*) houve diferença significativa a nível de $1 \%$ de significância $(\mathrm{p}<0.01$ ), o que significa dizer que esses dois parâmetros tem relação com o amadurecimento da cebola principalmente $b^{*}$ pois as cebolas tenderam para uma coloração mais amareladas. 
A análise de variância da cultivar 'população botucatu' revelou diferença significativa ao nível de $1 \%$ de significância ( $\mathrm{p}<0.01$ ) para os seguintes parâmetros: SST ( ${ }^{\circ}$ Brix), AT, pH, Relação SS/AT resultados presentes na Tabela 2 abaixo, tendo estes resultados uma correlação com o período de armazenamento.

Tabela 2. Síntese da análise de variância dos valores médios das características físico-químicas da cebola "População Botucatu" em temperatura ambiente.

\begin{tabular}{|c|c|c|c|c|}
\hline $\begin{array}{c}\text { Tempo de } \\
\text { armazenamento (dias) }\end{array}$ & $\mathrm{pH}$ & SS & Ratio & AT \\
\hline 0 & $5,55 \mathrm{ab}$ & $13,1 \mathrm{a}$ & $81,5 \mathrm{a}$ & $0,16 \mathrm{~d}$ \\
\hline 15 & $5,60 \mathrm{a}$ & $11,0 \mathrm{ab}$ & $49,8 \mathrm{bc}$ & $0,21 \mathrm{bc}$ \\
\hline 30 & $5,53 \mathrm{ab}$ & $11,0 \mathrm{ab}$ & $61,7 \mathrm{~b}$ & $0,24 \mathrm{ab}$ \\
\hline 45 & $5,49 \mathrm{bc}$ & $9,8 \mathrm{~b}$ & $40,5 \mathrm{c}$ & $0,24 a b$ \\
\hline 60 & $5,46 \mathrm{bc}$ & $11,6 \mathrm{a}$ & $44,5 \mathrm{bc}$ & $0,28 \mathrm{a}$ \\
\hline 75 & 5,44 & $12,6 \mathrm{a}$ & $54,6 \mathrm{bc}$ & $0,23 \mathrm{ab}$ \\
\hline Fator F & $0,88 \mathrm{~ns}$ & $5,14 * *$ & $13,2 * *$ & $13,9 * *$ \\
\hline CV\% & 1,05 & 12,74 & 17,96 & 13,0 \\
\hline
\end{tabular}

Médias seguidas de mesma letra na coluna não diferem pelo Teste de Tukey. ns: não significativo (P > 0,05); *: significativo (P < 0,05); **: significativo $(P \leq 0,01)$. $C V$ : coeficiente de variação $(\%)$. Fonte: Autores.

Analisando-se o pH e a acidez é possível observar que o conteúdo de compostos ácidos são baixos deixando o meio menos ácido. Então com isso o pH está diretamente ligado com o decrécimo da acidez e em contrapartida devidamente ligado a maturação dos bulbos e com o sabor das hortaliças (Chitarra \& Chitarra, 2005). Desta forma tais conceitos explicam a oscilação com relação a redução dos valores de $\mathrm{pH}$, resultados esses convergentes aos encontrados no trabalho de Costa et al. (2011) que também trabalharam com o armazenamento de cebolas.

Ao analisar os dados, o tempo de armazenamento não exerceu efeito significativo quando realizado o teste $\mathrm{F}$ a $5 \%$ de significância. De acordo com os dados obtidos na análise de variância para a variável SS, expressa em ${ }^{\circ}$ Brix, observou-se que as médias encontradas estão muito próximas, variando de 9,85 a 13,13 ${ }^{\circ}$ Brix.

Perda de Massa foi realizada durante os 75 dias de armazenamento, realizou-se seis avaliações entre nos dias 0,15 , 30, 45, 60 e 75 dias, após a colheita, no qual observou-se um aumento linear da perda de massa. A cebola armazenada em condição ambiente com 15 dias o valor de perda de massa foi de 1,86\%, com 30 dias de 5,44\%, com 45 dias de 7.10\%, com 60 dias de $8,37 \%$ e com 90 dias alcançou 16,20\% como descrito na Figura 1. Sendo que o aumento linear de perda de massa na cebola 'população botucatu' seguiu a resposta observada para a maioria dos genótipos de cebola (Lima et al., 2004). Aos 45 dias, a perda de massa já atingia 5\%, valor acima do qual começa a haver comprometimento da qualidade para a maioria das frutas e hortaliças. 
Figura 1. Perda de massa da cebola "População Botucatu" armazenada em temperatura ambiente em função do tempo.

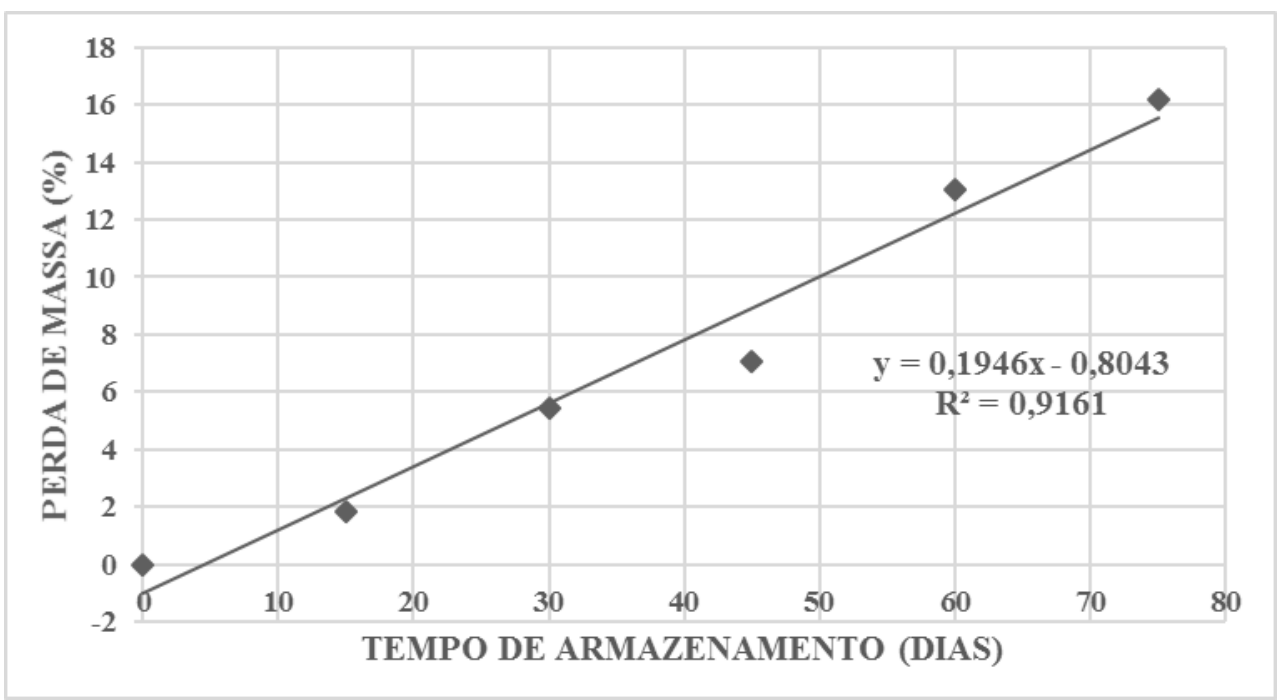

Fonte: Autores.

De acordo com Figueiredo Neto et al (2014), a cebola "Atacama" quando armazenados sob condições ambientes de $27 \pm 1^{\circ} \mathrm{C}$ e $50 \pm 5 \% \mathrm{UR}$, a perda de massa nos primeiros 15 dias foram de $2,73 \%$, valor inferior ao encontrado para a cebola 'população botucatu'. A perda de massa é um fator essencial ao armazenamento da cebola, pois causa diversos prejuízos econômicos, além do envelhecimento (Maia et al., 2000). A perda de umidade das cebolas armazenadas pela transpiração é devido a uma diferença de pressão de vapor ente o ambiente e o bulbo. A umidade relativa recomendada do ambiente é de $80 \%$, e um valor menor que esse vai promover uma maior perda de umidade pelo bulbo (Fernandes, 2017).

Diferenças na capacidade de armazenamento de diferentes cultivares de cebola também foram relatadas por Petropoulos et al. (2016), os quais destacam que características da cultivar podem afetar a capacidade de armazenamento dos bulbos, no qual o número e a espessura das camadas de túnicas e características da casca são fatores intimamente ligados à perda de massa.

No trabalho de Pereira et al. (2012) com armazenamento de cebolas em silos, o tratamento ambiente (T1) teve redução da firmeza tendo esse resultado devido a perda de água para o ambiente, isso em razão da umidade relativa apresenta níveis bem atos. Em razão disso a perda de firmeza pode esta relacionada diretamente a perda de massa fresca (Santos \& Araújo, 1979).

Na Figura 2 observa-se que o parâmetro de cor L* para a cultivar 'população botucatu' apresenta coloração de casca mais clara. O parâmetro de luminosidade ( $\left.\mathrm{L}^{*}\right)$, ou também conhecido como brilho da casca, varia de 0 a 100 , sendo o valor 0 , indicativo para coloração preta e o valor 100, do branco (Mcguire, 1992 \& Shewfelt, 1999). O brilho da casca da cebola é uma característica levada em consideração no momento da compra pelo consumidor, o qual possui como preferência, cebolas com coloração mais escura (Ferreira, 2000). 
Research, Society and Development, v. 10, n. 4, e19410413592, 2021

(CC BY 4.0) | ISSN 2525-3409 | DOI: http://dx.doi.org/10.33448/rsd-v10i4.13592

Figura 2. Brilho de casca da cebola "População Botucatu" armazenada em temperatura ambiente.

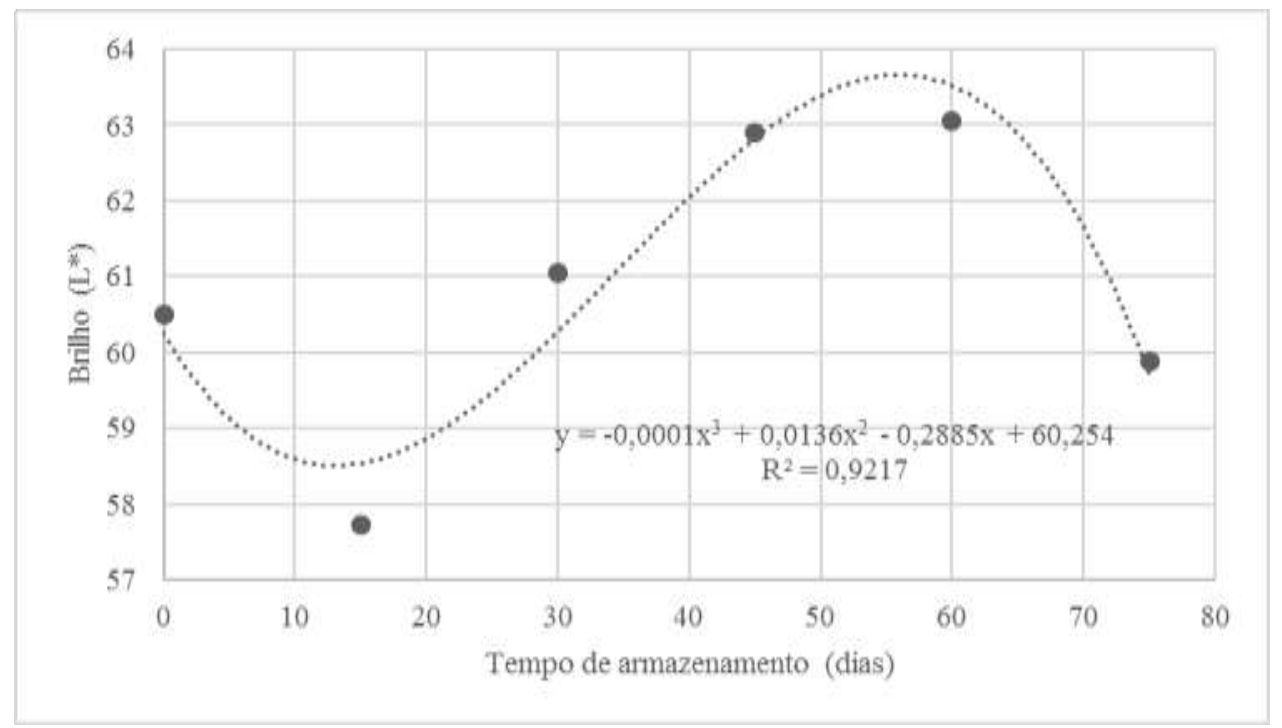

Fonte: Autores.

O resultado apresentado no presente trabalho, corrobora com o encontrado por Melo et al. (2010) que ao estudarem as alterações físicas em cebolas armazenadas sob refrigeração, constataram que houve aumento de luminosidade para as cultivares Beta Cristal e Óptima. Muniz et al. (2012), também relatam aumento de luminosidade para a cultivar CNPH6400 durante seu tempo de armazenamento sob refrigeração.

Observando a Figura 3, a coordenada a*, este parâmetro se encontra bem próximo da coloração vermelha.

Figura 3. Coordenadas a* da cebola "População Botucatu" armazenada em temperatura ambiente.

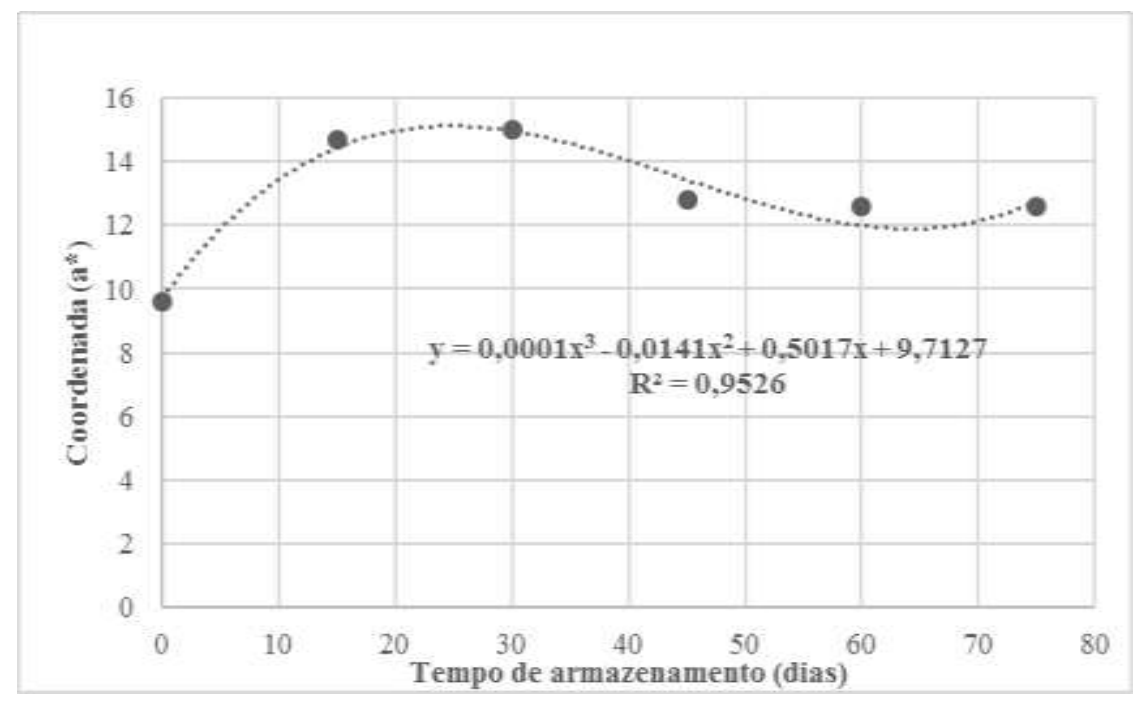

Fonte: Autores.

De acordo com a tabela colorímetria a qual demonstra uma escala de verde para valores a* negativos e vermelho a* positivo pode-se perceber que a cebolas obtiveram valores positivos, significando que as mesmas tenderam para um ton com traços vermelho-amarelados. A diferença entre cultivares de cebola para a coloração de casca é descrita por Petropoulos et al. (2016), como sendo características genéticas que são intrínsecas e independente do manejo adotado durante o cultivo.

Ressalta-se que o parâmetro de coloração b* como mostrado na Figura 4, demonstra redução durante os tempos de armazenamento. 
Figura 4. Coordenadas b* da cebola "População Botucatu" armazenada em temperatura ambiente.

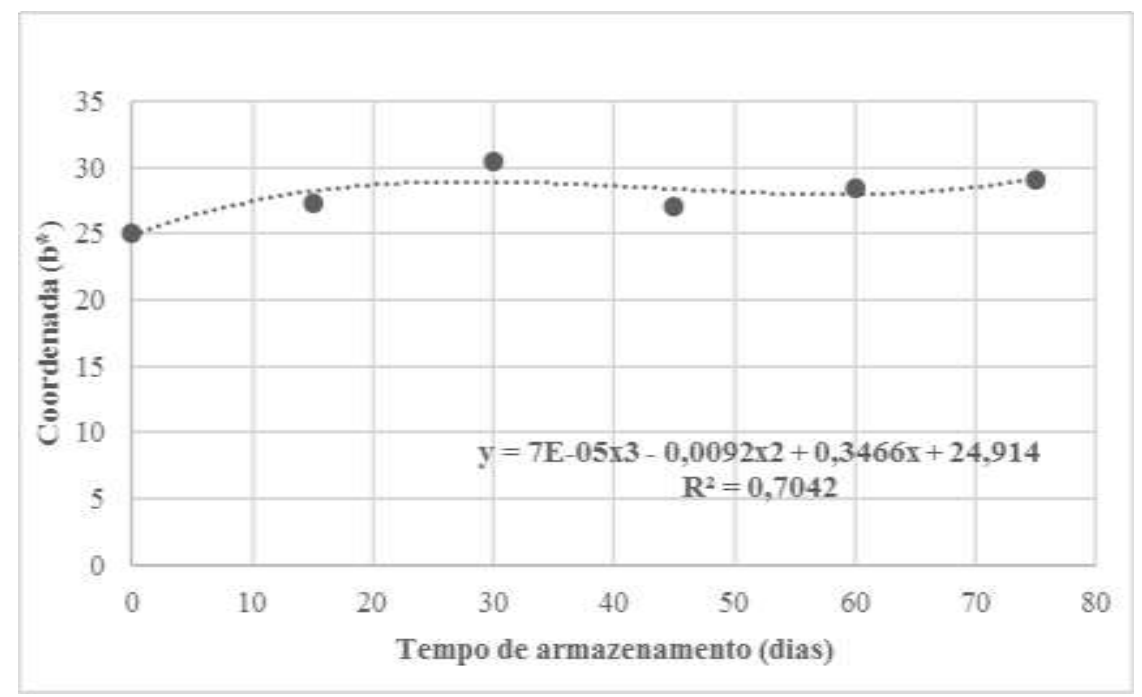

Fonte: Autores.

A perda das características de coloração do bulbo de cebola pode estar relacionada com a transferência de umidade do bulbo para a casca, no qual a umidade quando absorvida pela casca faz com que haja perdas de tonalidades. Observando o gráfico nota-se que não ocorre perda de umidade da 'população botucatu' durante o período de armazenamento.

Assim como o parâmetro $a^{*}$, na escala de $b^{*}$, temos colorações amareladas para $b^{*}$ positivo e cores azuladas para $b$ negativo. O conjunto de atributos químicos e físicos estão ligados a qualidade pós-colheita, no qual o produtor deve-se atentar às características requeridas pelos consumidores. A coloração é uma das principais características a serem analisadas no momento da compra, assim a perda exacerbada de determinado parâmetro durante o armazenamento, prejudica não só o consumidor, mas também o produtor que acaba recebendo menos pelo produto fornecido (Finger \& Casali, 2002).

A característica da coloração está ligada a genética da cultura, assim faz-se importante a seleção da cultivar levando em consideração e aceitação pelo mercado consumidor; seja in natura, processamento ou até mesmo para armazenamento (Granjeiro et al., 2008). Comparando os resultados obtidos com Dotto (2020), a cultivar Itajubá apresentou coloração de casca mais amarelada, com perda de 6,13\% do atributo durante seu armazenamento. As cultivares Mulata, BR29 e Rainha apresentaram maiores perdas durante o armazenamento, com 19,44, 18,42 e 17,73\%, respectivamente.

Na Figura 5 estão presentes os dados do pH, onde devido à acidez desses compostos, quanto maior seu conteúdo, mais ácido fica o meio e menor o pH (Berno, 2012). 
Figura 5. Valores de pH da cebola "População Botucatu" armazenada em temperatura em função do período de tempo.

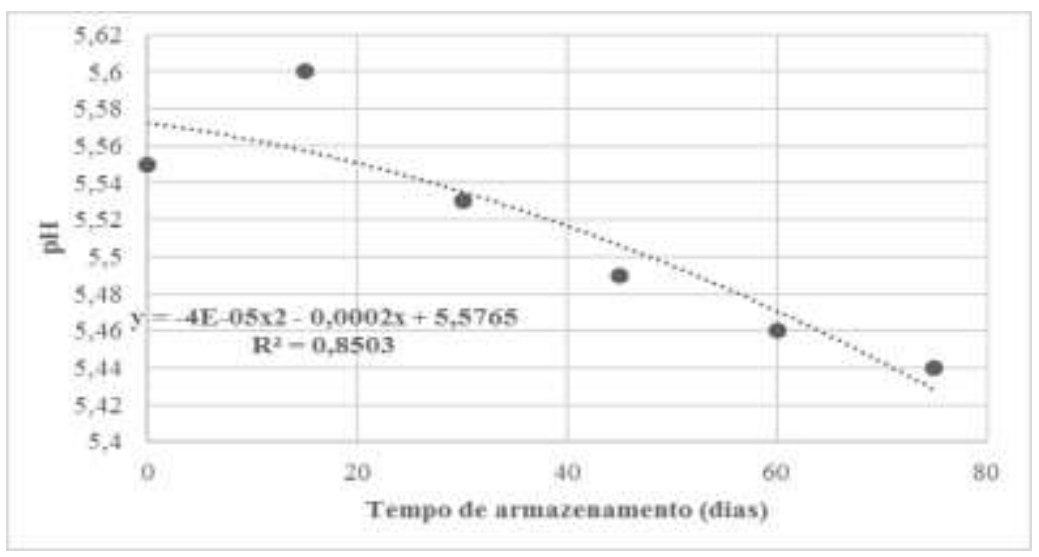

Fonte: Autores.

Estando o pH diretamente relacionado com o decréscimo da acidez ocorrida com o avanço da maturação dos bulbos, sendo, dessa forma, um indicativo de sabor de uma hortaliça, tendo relação inversa à acidez (Chitarra \& Chitarra, 2005).

Segundo Fernandes (2017), valores baixos de pH podem estar associados a ocorrência de repouso e dormência dos bulbos e, portanto, contribui para aumento no tempo de armazenamento. Da mesma forma que a acidez, o pH está vinculado com o nível de ácidos orgânicos. Devido à acidez desses compostos, quanto maior seu conteúdo, mais ácido fica o meio e menor o pH (Berno, 2012), estando o pH diretamente relacionado com o decréscimo da acidez ocorrida com o avanço da maturação dos bulbos, sendo, dessa forma, um indicativo de sabor de uma hortaliça, tendo relação inversa à acidez (Chitarra \& Chitarra, 2005).

De fato, isso explica o comportamento da cebola 'população botucatu'oscilando gradualmente com a diminuição do pH que variou de 5,50 no início do armazenamento a 5,44 com 75 dias de bulbos armazenados. Costa et al. (2011) também encontraram redução de $\mathrm{pH}$ ao longo do armazenamento em cebolas.

De acordo com Chitarra e Chitarra (2005) os sólidos solúveis são constituídos principalmente por açúcares, sendo variáveis com a espécie, cultivar, o estádio de maturação e o clima, com valores médios entre 8 e $14 \%$, que representam principalmente os açúcares solúveis presente nos alimentos, sendo muitas vezes usados como uma medida indireta de açúcares. De acordo com a Figura 6 é possível observar a grande variação desse parâmetro durante o período de armazenamento da cebola 'população botucatu'.

Figura 6. Teor de SS da cebola "População Botucatu" armazenada em temperatura ambiente em função do tempo.

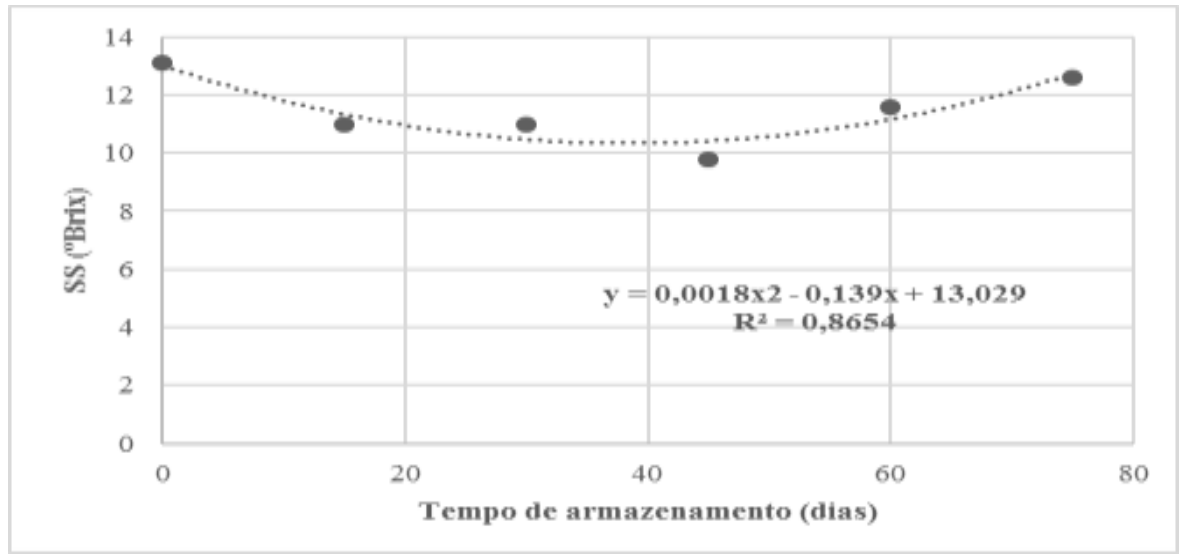

Fonte: Autores. 
Bandeira et al. (2013) estudando cinco cultivares de cebola (IPA10, IPA 11, Alfa São Francisco, Serena e Antares) sob quatro métodos de manejos de irrigação constataram valores de sólidos solúveis variando entre 9,2 a 10,2\%.

Segundo Lima et. al. (2004) o teor de sólidos solúveis para cebolas não sofre variações durante o armazenamento, corroborando com os resultados encontrados. Em Minas Gerais, Chagas et al. (2004) observaram maiores valores de SS para as cultivares Crioula, Pira Ouro, Jubileu e Baia Periforme, com variações de 12,68 a 13,10\%.

Para a relação SS/AT Figura 7, observou-se comportamento linear decrescente com o aumento do tempo de armazenamento (Figura 10), em virtude do aumento na acidez, em função do tempo de armazenamento, ser maior do que o observado para sólidos solúveis.

Figura 7. Ratio da cebola "População Botucatu" armazenada em temperatura ambiente.

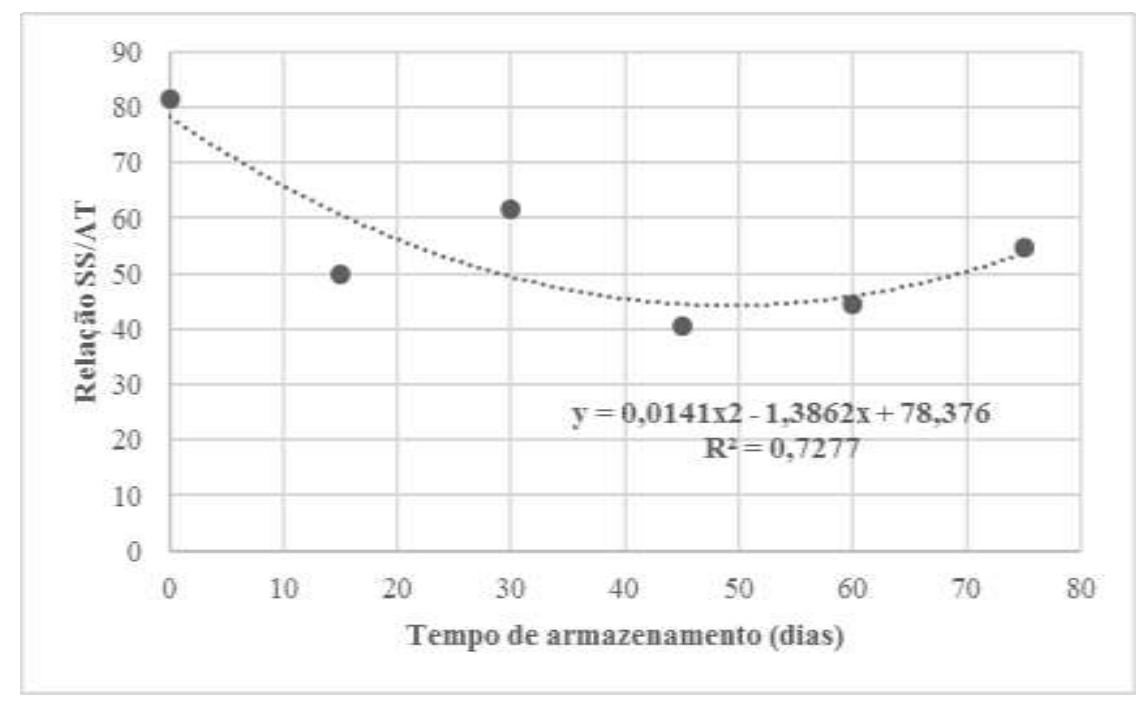

Fonte: Autores.

Muniz et al. (2012) durante os estudos com cultivares de cebola em tempos de armazenamento, descrevem um aumento na relação sólidos solúveis e acidez titulável, devido ao decréscimo na concentração dos ácidos orgânicos, indicando assim uma manutenção dos caracteres organolépticos das cebolas.

Para a acidez titulável a variedade de cebola 'população botucatu'apresentou valor médio de $0,22 \%$ de ácido pirúvico aos 75 dias de armazenamento como mostrado na Figura 8. Albuquerque et al. (2013) também encontraram resultados de acidez titulável bem próximos de 0,31\% trabalhando com variedade Red Creole Chata Roxa. Valores inferiores foram encontrados por Miguel e Durigan (2007) estudando a qualidade dos bulbos de cebola 'Superex' armazenados sob refrigeração, onde encontraram valores que não ultrapassaram $0,17 \%$ ao longo de 90 dias de armazenamento. 
Figura 8. AT da cebola "População Botucatu" armazenada em temperatura ambiente.

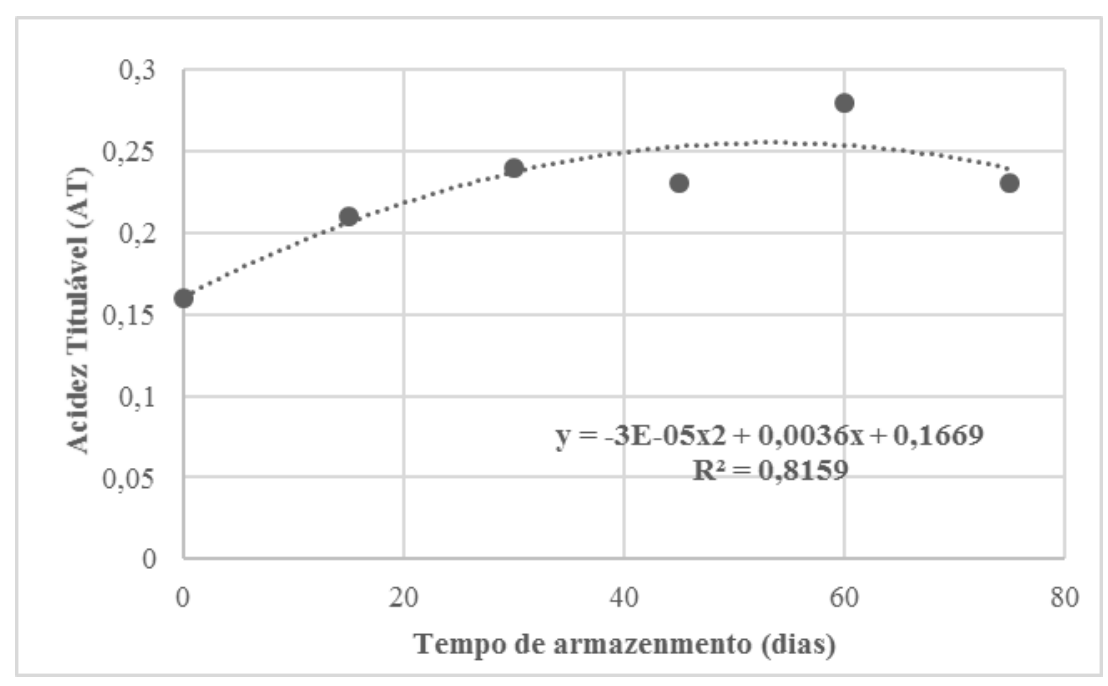

Fonte: Autores.

Schunemann (2006) ainda descreve que a intensidade do sabor também pode alterar-se durante o armazenamento, sendo que algumas cultivares de cebola podem aumentar ou diminuir a intensidade de pungência durante o armazenamento. Os bulbos de cebola que apresentarem esses teores elevados são considerados de melhores qualidades para a desidratação, em que partes desses compostos aromatizantes são perdidos durante esse processo (Chagas et al., 2004).

\section{Conclusão}

Observou-se que os bulbos armazenados em temperatura ambiente têm perdas de massa significativas em relação ao tempo de armazenamento principalmente a partir de 45 dias. O teor de sólidos solúveis não sofreu mudanças significativas durante o período de armazenamento tendo valor médio de $11,8^{\circ} \mathrm{Brix}$.

Desta forma, novos estudos envolvendo as condições de armazenamento e outras variedades são necessários para a compreensão das alterações na fase de pós colheita nos bulbos de cebolas. Sendo assim este trabalho foi um ponto inicial tornando-se referência para outras pesquisas desenvolvidas com este mesmo produto.

\section{Agradecimentos}

O presente estudo foi realizado com apoio da Universidade Federal do Vale do São Francisco e da Embrapa Semiárido-PE.

\section{Referências}

Albuquerque, J. R. T., Costa, F. B., Pereira, E. M., Rocha, T. C., \& Lins, H. (2013). A Qualidade Pós-Colheita da Cebola Roxa Produzida no Sertão Paraibano. Revista Verde de Agroecologia e Desenvolvimento Sustentável, 8, 17 -21.

Araújo, J. L. P., \& Correia, R. C. (2007). Cultivo da cebola no Nordeste: economia. Empresa Brasileira de Pesquisa Agropecuária, 2007. http://sistemasdeprodução.cnptia.embrapa.br/FontesHTML/Cebola/CultivoCebolaNordeste/custos.htm.

APG (Angiosperm Phylogeny Group). (2001). An update of the angiosperm Phylogeny Group classification of the orders and families of flowering plants: APG II. Botanical Journal of the Linnean Society, 141(4), 399-343.

Bandeira, G. R. L., Queiroz, S. O. P. de; Aragão, C. A.; Costa, N. D., \& Santos, C. A. F. (2013). Desempenho agronômico de cultivares de cebola sob diferentes manejos de irrigação no Submédio São Francisco. Irriga, 18, 73 - 84.

Beerli, K. M. C., Vilas Boas, E. V. B., \& Piccoli, R. H. (2004). Influência de sanificantes nas características microbiológicas, físicas e físicoquímicas de cebola (Allium cepa L.) minimamente processada. Ciência Agrotecnologia, 28, 107-112. 
Berno, N. D., Baldassin, S., Oliveira, G. S., Oliveira, J., \& Kluge, R.A. (2012). Microbiologia de cebola 'Crioula' vermelha minimamente processada armazenada sob diferentes temperaturas. XXIII Congresso Brasileiro de Ciência e Tecnologia de Alimentos. Centro de Convenções da UNICAMP Campinas-SP, Brasil.

Boeing, G. (2002). Fatores que afetam a qualidade da cebola na agricultura familiar catarinense. Florianópolis: Instituto CEPA/SC, 80 p.

Brecht, J. K.; Saltveit, M. E.; Talcott, S.T., \& Moretti, C. L. (2007). Alterações metabólicas. In: Moretti, C. L. Manual de processamento mínimo de frutas e hortaliças. Embrapa Hortaliças, 531p.

Brewster, J. L. (2008). Onions and outher vegetable alliums. In Brewster, J. L. (Ed.). The classification, origins distribution and economic importance of the major vegetable crops. (2a ed.), Wallingford: $C A B I, 1,1-222$.

Cassaro, K. P., \& Durigan, J. F. (2000). Hortaliças minimamente processadas. Horticultura Brasileira, 18, 159-161.

Congresso Nacional De Irrigação E Drenagem. (2015). São Cristóvão Agricultura irrigada no Semiárido brasileiro: anais. São Cristóvão: ABID: Universidade Federal de Sergipe, 1 CD-ROM.

Chagas, S. J. R., Resende, G. M., \& Pereira, L.V. (2004). Características qualitativas de cultivares de cebola no sul de Minas Gerais. Ciência Agrotécnica, 28, 102-106.

Chitarra, I. M. F, \& Chitarra, A. B. (2005). Pós colheita de frutas e hortaliças: fisiologia e manuseio. UFLA, p. 681.

Dotto, L. (2020). Semeadura direta de cebola: plantabilidade, desempenho de cultivares e características físico-químicas na conservação pós-colheita (Dissertação de mestrado). Universidade Tecnológica Federal do Paraná, Paraná, Brasil.

EPAGRI. Sistema de produção para a cebola: Santa Catarina. (2013). (4.Revisão). Florianópolis: 106p. (Epagri. Sistemas de Produção, 46).

FAOSTAT. 2013. Food and Agricultural Organization of United Nation. www.fao.org/faostat/en/\#home.

Fernandes, B. C. C. 2017. Conservação pós-colheita em função da adubação potássica (Dissertação de Mestrado). Universidade Federal Rural do Semi-árido, Mossoró, Brasil.

Ferreira, M. D. (2000). Cultura da cebola: recomendações técnicas. Asgrow Seed Company, p. 25.

Figueiredo Neto, A.; Bandeira, G. R L., Olivier, N. C; Teixeira, R. A. (2014). Qualidade pós-colheita de cebola 'atacama' produzida com diferentes dosagens de nitrogênio. Revista Brasileira de Agropecuária Sustentável, 4, 76-82.

Finger, F. L., \& Casali, V. W. D. (2002). Colheita, cura e armazenamento da cebola. Informe Agropecuário. 23, 93-98.

Granjeiro, L. C., Souza, J. O, Aroucha, E. M. M., Nunes, G. H. S., \& Santos, G. M. (2008). Características Qualitativas de Genótipos de Cebola. Revista Ciência Agrotécnica, 32,. 1087-1091.

Instituto Brasileiro De Geografia e Estatistica - IBGE. 2017. Levantamento sistemático da produção agrícola - LSA. https://www.ibge.gov.br/estatisticas/economicas/agricultura-e-pecuaria/9201-levantamento-sistematico-da-producao-agricola.html?=\&t=o-que-e.

Instituto Centro de Economia e Planejamento Agrícola - ICEPA. Santa Catarina/Epagri. Dados e Informações - Balanço de oferta e demanda - safras 2012/13. Florianópolis: Epagri/Cepa, 2014. https://cepa.epagri.sc.gov.br/?s=Balan\%C3\%A7o+de+oferta+e+demanda+\%E2\% $80 \% 93+$ safras $\%$ E2\% $\% 0 \% 93+2012 \% 2 \mathrm{~F} 13$.

Instituto Adolfo Lutz - IAL. (2008) Métodos físico-químicos para análise de alimentos. (4a ed.), Instituto Adolfo Lutz, 2008.

Lima, M. A. C., Costa, N. D., Abe, M. A., \& Trindade, D. C. G. (2004). Qualidade e conservação pós-colheita de genótipos de cebola cultivados no Vale do São Francisco. In: Congresso Brasileiro De Olericultura, 44.

Maia, M. C. C., Pedrosa, J. F., Torres filho, J., Negreiros, M. Z., \& Bezerra neto, F. (2000). Características de qualidade de cebola múltipla durante armazenamento sob condição ambiental não controlada. Horticultura Brasileira, 18, 61-64.

Marconatto, L. J., Koehler, H. S., \& Marcuzzo, L. L. (2017) Caracterização dos produtores e das perdas de cebola durante a armazenagem na região do Alto Vale do Itajaí/SC. Summa hytopathologica, 43, 243-245.

Mcguire, R.G. (1992). Reporting of objective color measurements. Hort Science, 27, 1254-1255.

Melo, P. C. T., Breda júnior, J. M., \& Melo, R. A. (2010). Retrospectiva e avanços da cebolicultura brasileira na década de 2000. Revista Nosso Alho 6, 44-52.

Miguel, A. C. A., \& Durigan, J. F. (2007). Qualidade dos bulbos de cebola 'Superex’ armazenados sob refrigeração, quando expostos à condição ambiente. Horticultura Brasileira, 25, 301-305.

Muniz, L. B., Moretti, C. L., \& Matos, L. M. (2012). Caracterização física e química de duas cultivares de cebola armazenadas sob refrigeração. Revista de Ciências Agrárias, 35, 261-273.

Petropoulos, F., Kourentzes, N., Nikolopoulos, K., \& Siemsen, E. (2018). Judgmental selection of forecasting models. Journal of Operations Management, 60, $34-46$.

Santos, J. P. (2018). Desempenho de cultivares de cebola em função do espaçamento entre plantas. Rev. bras. eng. agríc. ambient. 2. 
Research, Society and Development, v. 10, n. 4, e19410413592, 2021

(CC BY 4.0) | ISSN 2525-3409 | DOI: http://dx.doi.org/10.33448/rsd-v10i4.13592

Shewfelt, R.L. (1999). What is quality Postharvest Biology and Technology, 15, 197-200.

Shünemann, A. P., Treptow, R., Leite, L. D., \& Vendruscolo, J. L. (2006) - Pungência e características químicas em bolbos de genótipos de cebola (Allium cepa L.) cultivados no alto Vale do Itajaí, SC, Brasil. Revista Brasileira de Agrociência, 12, 77-80.

Silva, F. de A. S., \& Azevedo, C. A. V. (2016). The Assistat Software Version 7.7 and its use in the analysis of experimental data. African Journal of Agricultural Research, 11, 3733- 3740.

Superintendencia de estudos econômicos e sociais da Bahia - SEI SENACE (2011). Seminário Nacional de Cebola.. 